\title{
Application and effect of plant growth promoting bacteria isolated from medicinal plants on root development in maize
}

Syed Sikandar Habib ${ }^{*}$, Saira Naz ${ }^{1}$, Asad Mehmood ${ }^{2}$, Riaz Khan ${ }^{2}$ and Imran Badshah ${ }^{2}$

1. Department of Biological Sciences, University of Sargodha Sub Campus Mianwali Punjab-Pakistan

2. Department of Botany, Pir Mehr Ali Shah, Arid Agriculture University Rawalpindi Punjab-Pakistan

*Corresponding author's email: Sikandarzoo00@yahoo.com

Citation

Syed Sikandar Habib, Saira Naz, Asad Mehmood, Riaz Khan and Imran Badshah. Application and effect of plant growth promoting bacteria isolated from medicinal plants on root development in maize. Pure and Applied Biology. Vol. 8, Issue 4, pp2277-2285. http://dx.doi.org/10.19045/bspab.2019.80174

\begin{tabular}{llll}
\hline \hline Received: 27/05/2019 & Revised: 15/07/2019 & Accepted: 22/07/2019 & Online First: 03/08/2019 \\
\hline
\end{tabular}

\section{Abstract}

Agriculture sectors are facing various threats that hinder plant growth globally. In order to improve plant growth the use of beneficial microbes play very important role. The purpose of the current study was to analyze the root development by the application of Plant growth promoting bacteria (PGPB). The importance of this study was to enhance the root development of maize plant which in turn increases its overall growth and production by using PGPB. The experiment was conducted under complete randomized design (CRD). Two varieties of Cereal crop maize were selected to check the effects of PGPB on development of roots. Initially seeds were inoculated with eight different bacterial strains that were isolated previously in Plant microbe interaction lab. Out of which two bacterial strains R7 and R8 found to be more efficient in promoting different activities of plants which affect the root development. Plants were grown in pots after inoculation. Five different treatments were applied and the six one was control and after harvesting parameters of roots to be analyzed were taken. Five different parameters of roots were observed after harvesting. These parameters include Average root width, Network depth, maximum number of roots, specific root length and network area. Estimation of root parameters was done with the help of GiA root software. GiA software is a new technique to analyze Root System Architecture (RSA) traits. Results were variable after the inoculation of bacterial strains which prove that the PGPB have positive effects on root development and hence all over the plant growth.

Keywords: Bacterial strains; GiA software; Maize; PGPB

Introduction

Crop production had been improved by using soil microbes from many years. In recent times, mineralization of organic pollutants has been increased by using bacteria in soil that is called as bioremediation of polluted soil [1].

At this time, the application of biological techniques is getting popularity as they are added as a helper to chemical fertilizers in 
order to increase plant growth and yield of crops in an incorporated plant nutrient system. In this contest PGPB (Plant growth promoting bacteria) has gain a vital part in building maintainable systems for crop production [2]. A wide range of nonsymbiotic bacteria that include Azospirillum, Azotobacter, Klebsiellasp and Bacillus etc. Also the symbiotic bacteria including species of Rhizobium are applied all over the world in order to achieve increased plant growth and production rate [3].

Plant growth promoting bacteria are the type of bacteria which can increase growth of plants by a range of procedures e.g. phosphatesolubilization, biological nitrogen fixation, siderophore production, rhizosphere etc. Studies prove that there are some bacteria that remain attached to plants have the capability to boost plant growth [4]. These microorganisms have got attention for the reason that now a day most remarkable need is to decrease the practice of chemicals especially when seeing the condition of maintainable cultivation and environmental protection [5]. Plant growth promoting bacteria have the capability to help in the development and growth of maintainable agricultural systems [6].

Main objectives of the current study was the application of already isolated PGP (Plant growth promoting bacteria) strains to check their root growth promotion activities and understand effects of PGP bacteria on root architecture of maize plants.

\section{Materials and methods}

The current experiment was performed in the laboratory of Plant Sciences, University of Sargodha Sub Campus Mianwali. Previously isolated strains from the medicinal plants in the Plant Microbe Interaction were used in the study. Bacterial strains were used to evaluate their influence on plant root development.

\section{Preparation of Inoculum and soil sterilization}

Two previously isolated bacterial strains (R7 and R8) were used for inoculum preparation. Luria Bertani (LB) was used in quantity of $100 \mathrm{ml}$ to inoculate both strains separately at $120 \mathrm{rpm}$ for time of 48 hours and temperature given was 30 for the purpose of incubation. After incubation, centrifugation of broth culture was performed at $3000 \mathrm{rpm}$ for 10 minutes. After this, pallets were collected and distilled water was used to re-suspend these pallets in order to obtain optical density equal to 1 at $600 \mathrm{~nm}$. This suspension was then used to soak seeds before their sowing [7].

Ethanol (95\%) was used for the purpose of surface sterilization by dipping them in it for few seconds after that seeds were dipped in $0.2 \%$ solution of $\mathrm{HgCl}_{2}$ for three minutes and then carefully rinsed off with distilled water [8]. After surface sterilization of seeds, they were soaked in already prepared bacterial inoculum for time period of 3 - 4 hours prior to sowing whereas seeds for application of control treatment were soaked only in distilled water. Autoclaved soil was filled in pots with the capacity of $5 \mathrm{~kg}$ for sowing two varieties of two maize seeds whereas ratio of autoclaved soil, sand, vermin compost was kept $(1: 1: 1)$ in pots.

\section{Pot experiment}

Pot experiment was performed in order to characterize the capability of previously isolated bacterial strains in promoting the growth of plants and to check their influence on root development. Total eight isolates of bacteria were previously isolated named as R1, R2, R3, R4, R5, R6, R7, and R8. Among all these eight strains of bacteria only two strains R7 and R8 showed best performance. So, these two previously isolated bacterial strains i.e. R7 and R8 were picked to use in pot experiment because of their high PGP activity. 
Design used for pot experiment was complete randomized design (CRD) and the arrangement was kept factorial and number of replicates was three. Two varieties of maize seeds that were used during this experiment named as TP-1217 (Variety 1) and TP-1221 (Variety 2) were gained from NARC, Crop Research Institute as this experiment was carried out National Agriculture Research Centre (NARC)

Treatments application

The schedule of treatments for both varieties (TP-1217=V 1) and (TP-1221=V 2) was kept same and the conditions applied were also same in below (Table 1).

After the time period of 60 days of germination and 15 days of disease application plant were harvested. Immediately after harvesting different physiological parameters was taken. These physiological parameters include average root width (diameter), network depth, maximum number of roots, specific root length and network area.

Table 1. Experimental treatments

\begin{tabular}{|c|c|}
\hline Abbreviations & Treatments \\
\hline C & Control \\
\hline T1 & Bacteria R7 (B1) was applied \\
\hline T2 & Bacteria R8 (B2) was applied \\
\hline T3 & Bacteria R7+disease was applied (B1D) \\
\hline T4 & Bacteria R8+disease was applied (B2D) \\
\hline T5 & Only disease was applied (D) \\
\hline
\end{tabular}

\section{Estimated parameters of roots}

Different parameters can be estimated by using GiA software. But here in this study five parameters were observed that are Average root width also called as diameter was taken of freshly harvested plants. The scale used was in $\mathrm{cm}$ and measuring tape was used to take diameter [9]. Second parameter taken was network depth. It was also taken of freshly harvested plants in centimeter. Number of roots was noted immediately after harvesting of plants. Maximum number of roots was taken in $(\mathrm{n})$. The $4^{\text {th }}$ parameter was specific length of roots. Length of roots was measured by using measuring tape and the scale used to take specific root length was centimeters [10]. Network area is the last parameter which was measured by using freshly harvested plants and the scales used were square of $\mathrm{cm}\left(\mathrm{cm}^{2}\right)$.

\section{Statistical analysis}

All the data obtained from experiments was collected and then deduced and analyzed by using version 8.1 of Statistics. Two-way
ANOVA was used for this purpose. Least significance difference test (LSD) was used to test significance of treatments mean which was $\mathrm{p} \leq 0.05$.

\section{Results}

Estimation of roots using GiA roots software discovered many prime phenotypic parameters of roots by rice roots. Analysis of traits of roots by using root system architecture (RSA) may help out in deep vision of phenotype of rice roots and in turn it leads to the formation of new paths for better understanding of various hidden aspects of root development. Therefore, in recent study, GiA roots software was used in order to analyze a large number of images of rice roots. As a result of these processed images of 14, 21 and 28 days old rice roots was generated. The results showed there was an increase in different parameters of root development. Similarly, an increase in root parameters were observed in roots of maize also which was used to analyze RSA (root surface architecture) of roots by rice roots. 


\section{Average root width (Diameter)}

Results show that there is an increase in root width of both maize varieties V1 (TP-1217) and V2 (TP-1221) in below (Figure 1). When treatment was given with bacterial strains R7 and R8. On the other hand, when the plants were inoculated with bacterial strains along with disease application, the rate of increase in average root width of both analysis of traits of roots leads to the formation of new paths for the development.

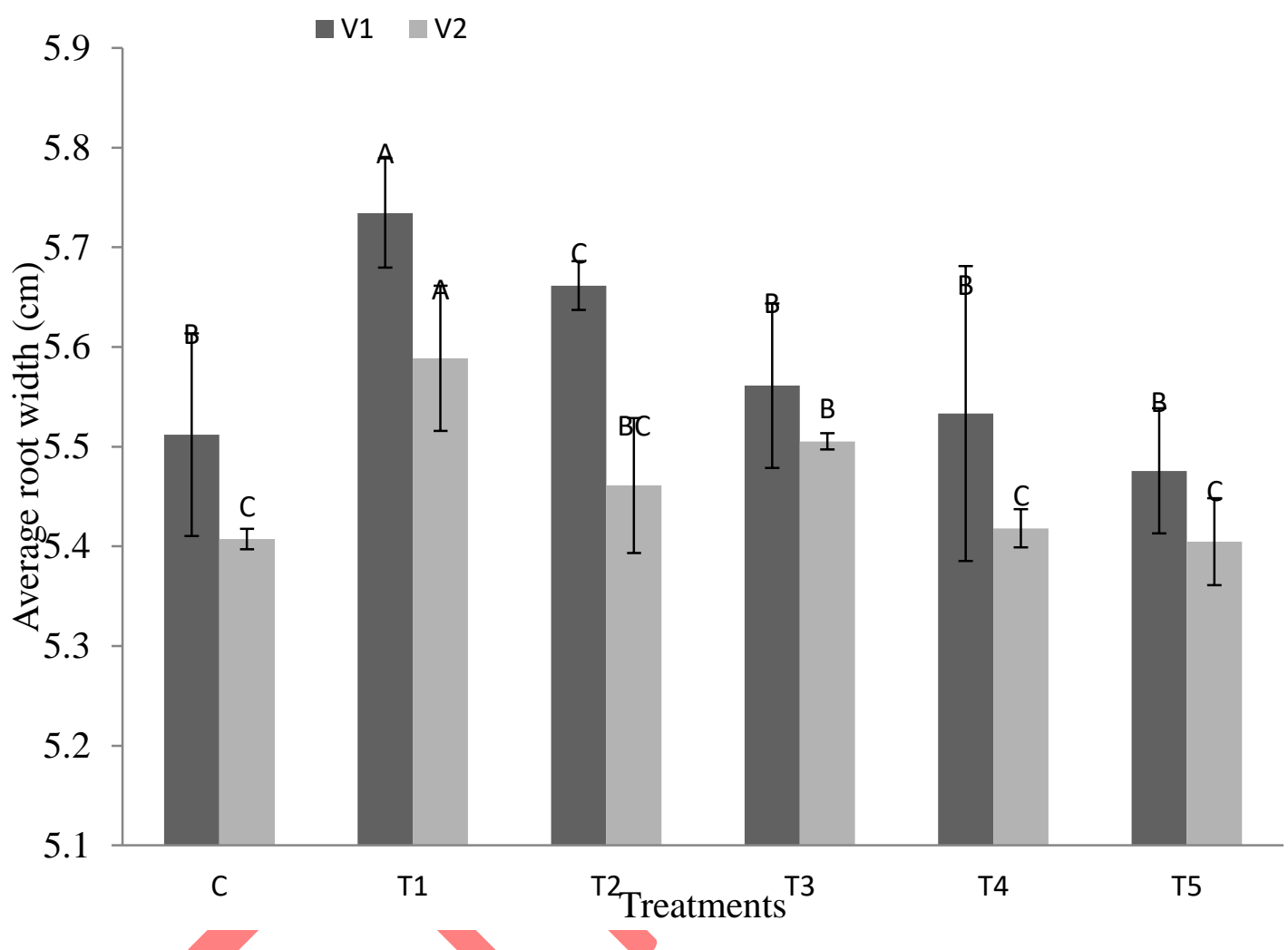

Figure 1. Average increase in root width a width after treatment with bacteria

\section{Network depth}

Results for network depth are different. Treatment with bacterial strain R7 (B1) cause a slight decrease in network depth in roots of both varieties of maize but when treated with bacterial strain R8there was an increase in network depth of both varieties. Afterward in treatments T3, T4 and T5 in plants of maize network depth of roots continuously increase as a result increasing the growth rate of these plants in (Figure 2). 


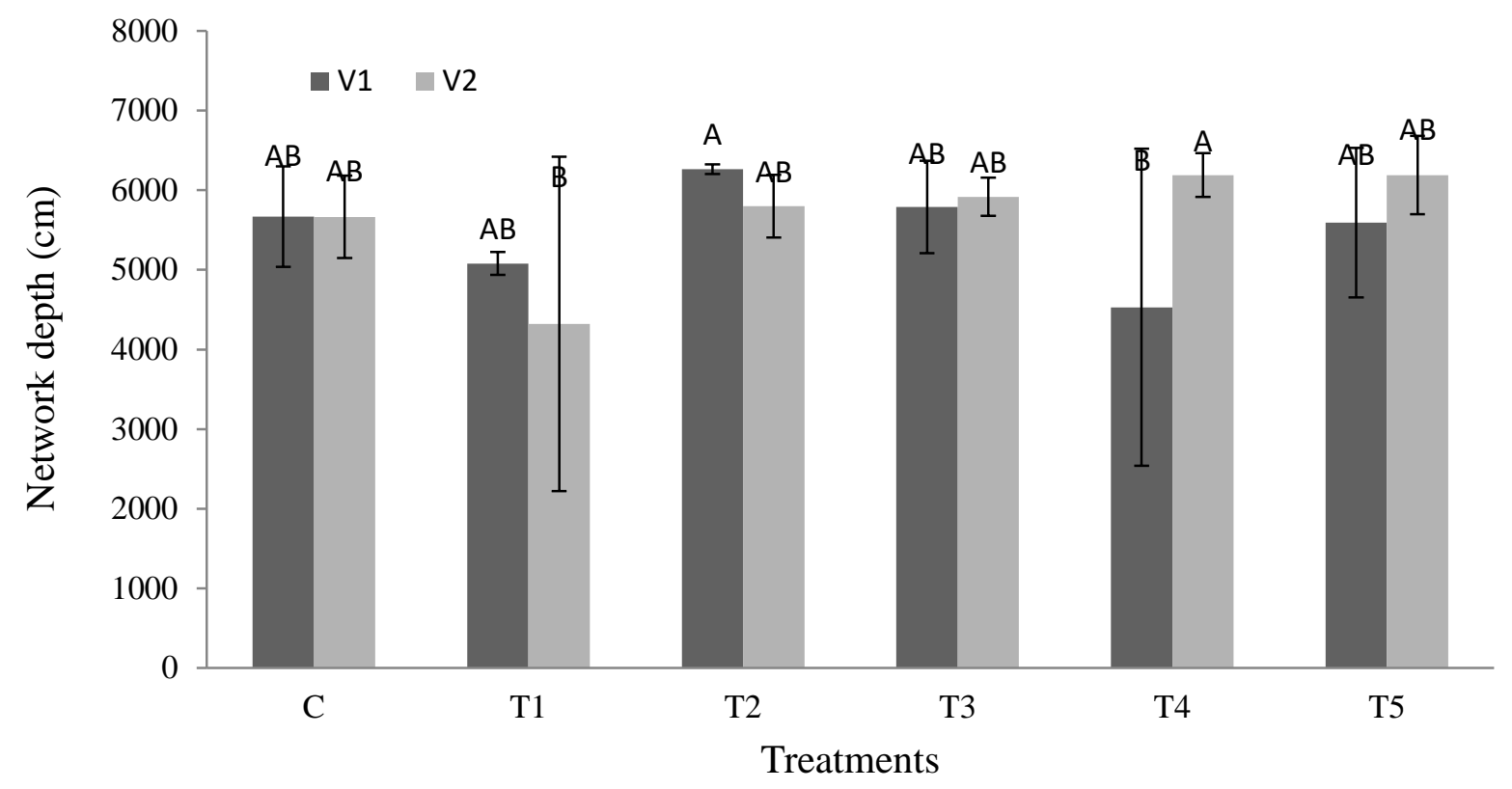

Figure 2. Network depth of roots by treatments with different bacterial strain

\section{Maximum number of roots}

Numbers of roots were only increased in treatment named as T2 in both varieties (TP1217) and (TP-1221) so in this case the growth of plants was better than the other plants. Control, T3, T4and T5 have almost same development of roots but plants treated with T4 and T5 have almost same development of roots but plants treated with bacterial isolate R7 have shown decrease in number of roots in (Figure 3).

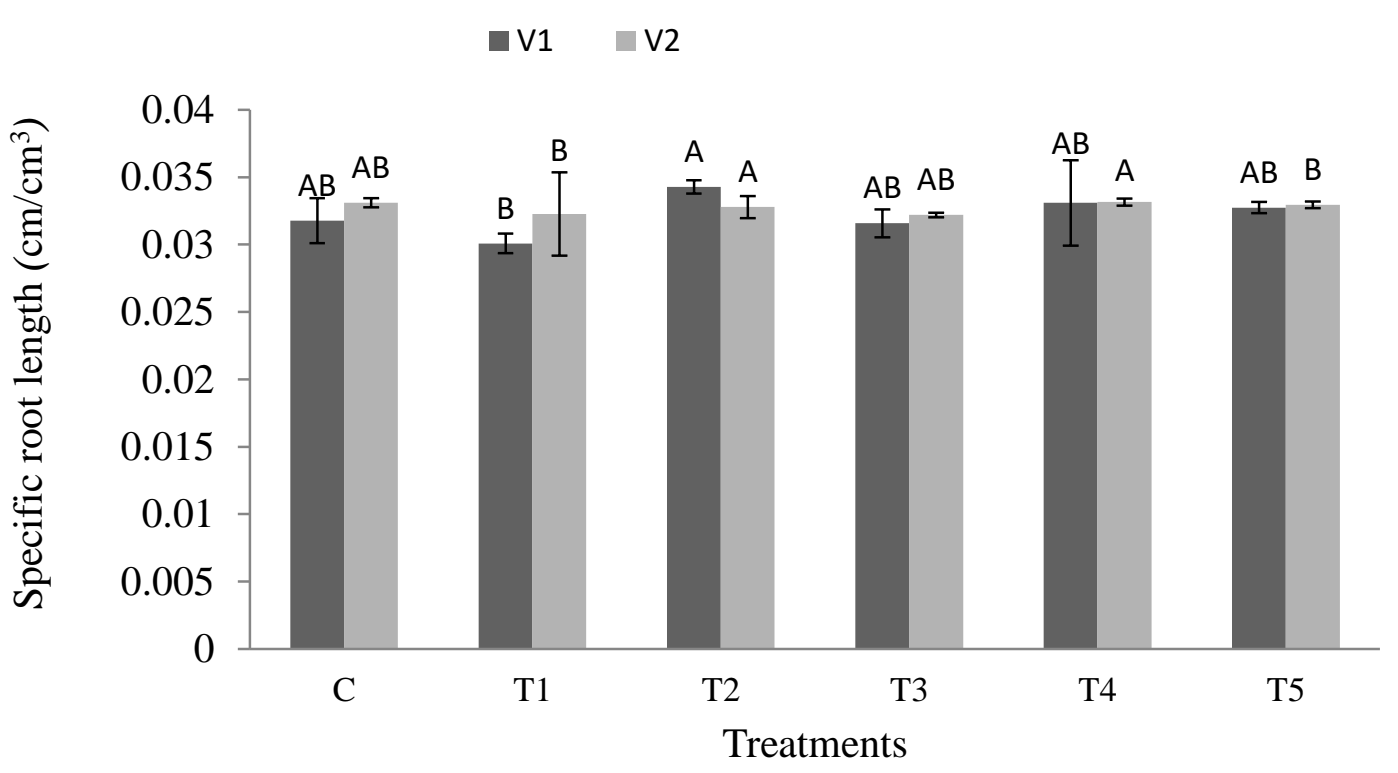

Figure 3. Roots development of plant by treatment with bacteria 


\section{Specific root length}

A massive increase in root length was observed in all plants of variety V1 (TP1217) and variety V2 (TP-1221). Graph shows that change in length of roots of all plants was almost same. In all cases of bacterial strain application, the length of roots almost remains consistent. This is proved that both bacterial strains R7 and R8 help the maize plants to increase their length of roots in treatment $\mathrm{T} 1, \mathrm{~T} 2, \mathrm{~T} 3, \mathrm{~T} 4$ and $\mathrm{T} 5$ as well as to maintain their root length that helps the plants to increase their mineral uptake in below (Figure 4).

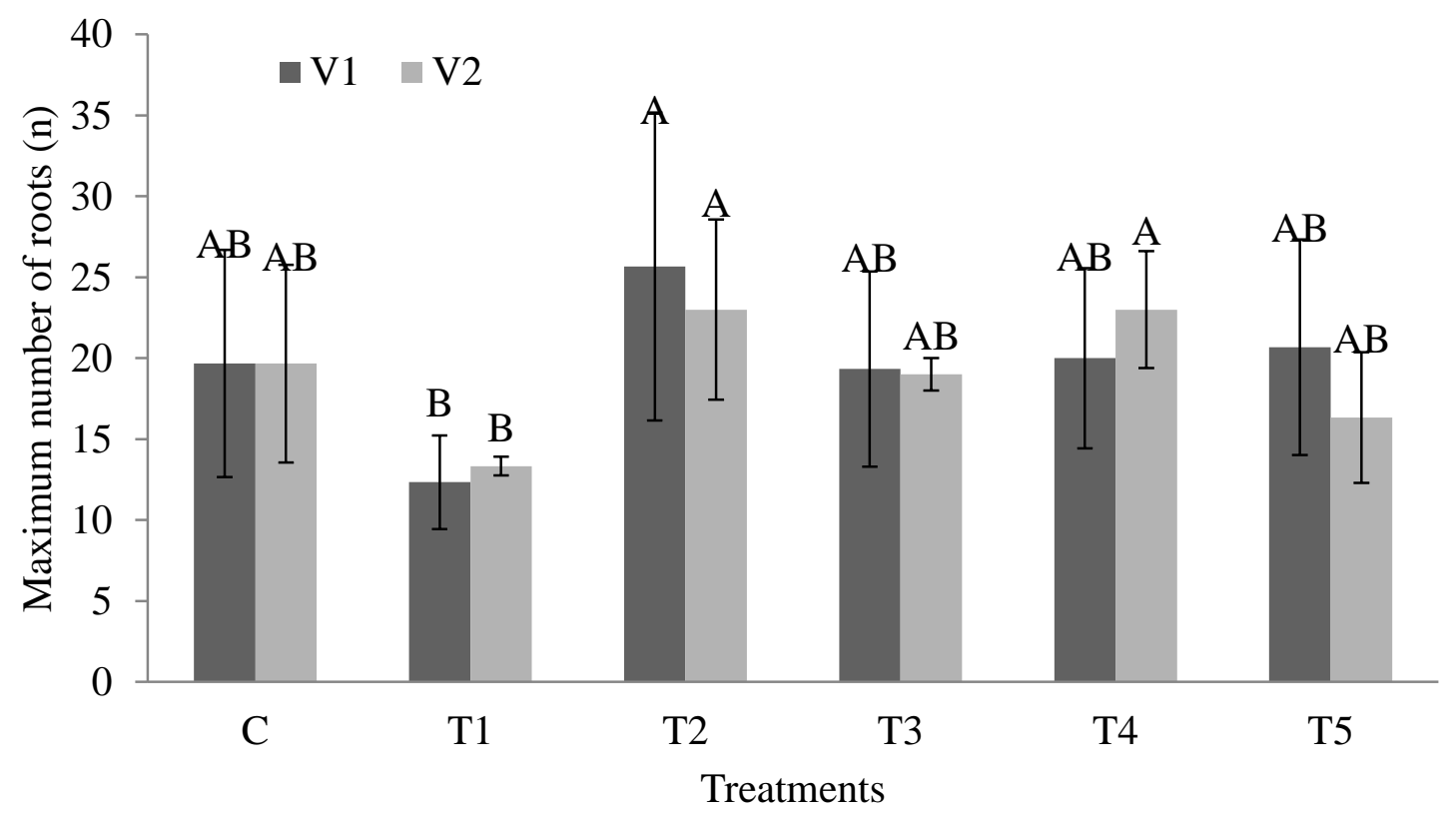

Figure 4. Specific root length of plants by treatment with bacteria

\section{Network Area}

Bacterial strain R8 (B2) only cause positive effects in network area. But R7 that is bacteria strain named as B1 showed negative effects in development of network area of roots as network area of plants of $\mathrm{T} 1$ was greatly decreased when treated with bacterial strain B1 in both varieties. After that in case of bacterial strain R8 network area of roots of maize increased greatly in two varieties (TP1217) titled as V1 and (TP-1221) named as V2. But network area decreased after the application of bacterial strains along with disease in (Figure 5). 


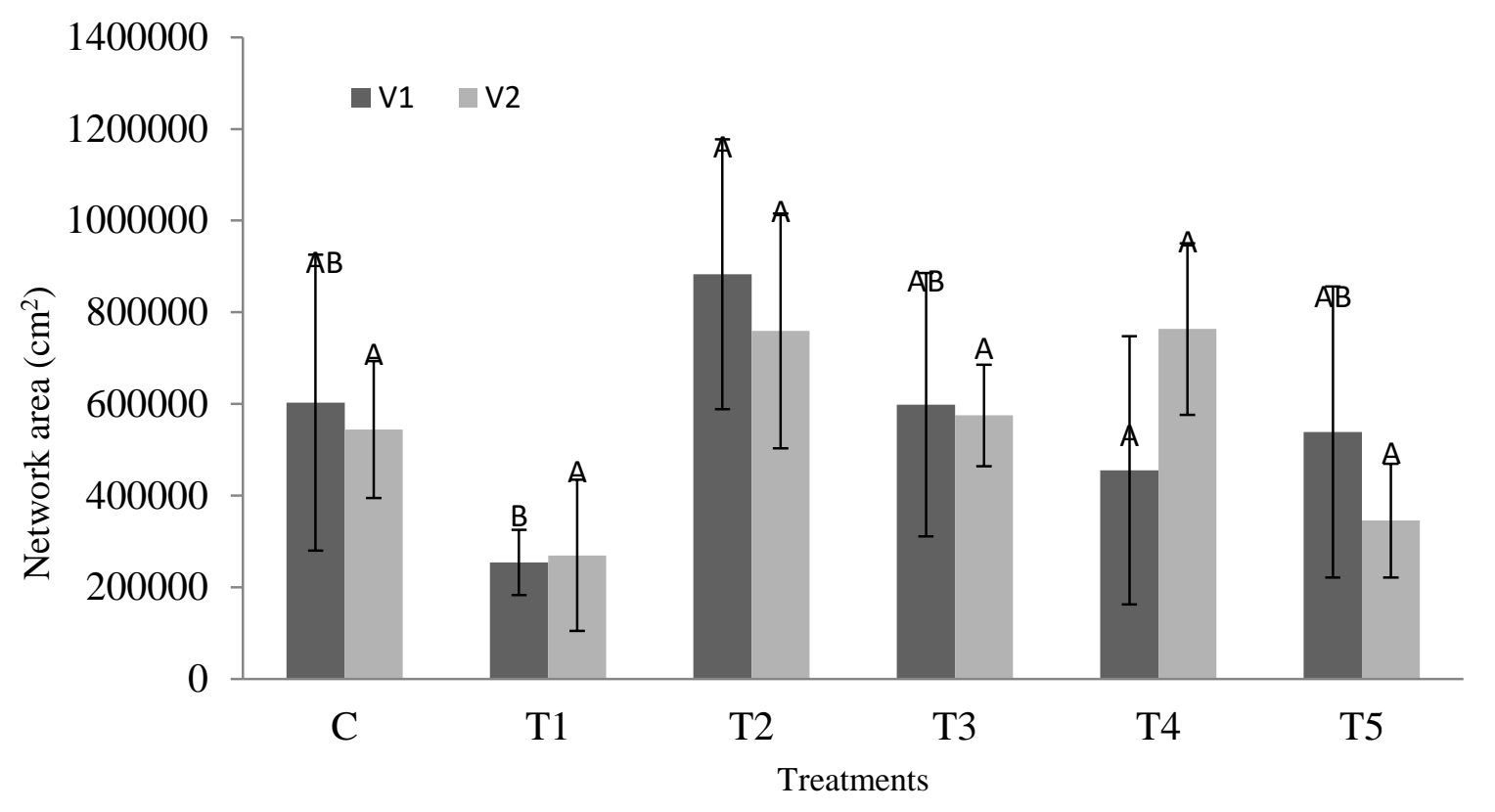

Figure 5. Network area of plant root by treatment with different bacterial strains

\section{Trait description}

All the traits used for estimation were described in their measurement scale. Their estimation was described with the help of graphical explanations. In graphs the growth rate of roots of maize were described in the form of bars. These bars clearly show the developmental changes of all the parameters of roots of maize in both varieties V1 (TP1217) and V2 (TP-1221). As the roots showed developmental changes that's why with the help of two colored bars these changes were explained in below (Table 2).

Table 2. Description of traits

\begin{tabular}{|c|c|c|}
\hline Traits & Description & Units \\
\hline $\begin{array}{c}\text { Average root } \\
\text { width }\end{array}$ & $\begin{array}{c}\text { This trait is parallel to the diameter of roots. In whole root system, the } \\
\text { mean value of root width for all the pixels of medial axis is estimated. }\end{array}$ & $\mathrm{Cm}$ \\
\hline $\begin{array}{c}\text { Maximum } \\
\text { number of roots }\end{array}$ & $\begin{array}{c}\text { The maximum number is measured as 1 standard deviation }\left(84^{\text {th }} \text { - }\right. \\
\text { percentile value), after concluding the number of roots intersecting a } \\
\text { horizontal line from smallest to largest. It is denoted by (MaxR). }\end{array}$ & $\mathrm{N}$ \\
\hline
\end{tabular}

\section{Discussion}

Result analysis of the present study showed that R7 and R8 have the ability to produce siderophore, as well as R3, R7 and R8 are capable of produce ammonia. Bacterial strains $\mathrm{R} 1, \mathrm{R} 2, \mathrm{R} 4, \mathrm{R} 7$ and $\mathrm{R} 8$ are found to be involved in Phosphate solubilization whereas R2, R4, $\mathrm{R} 5, \mathrm{R} 7$ and R8 have IAA production ability. Among all bacterial strains only $\mathrm{R} 7$ and $\mathrm{R} 8$ found to have oxidase production ability and along with R7, R8, R3 is also involved in amylase production. Zinc solubilization ability is shown by R1, R2, R3, R4, R5, R6 and R7. Bacterial strains R4, R7 and R8 played their role in pectinase production and $\mathrm{R} 1, \mathrm{R} 4, \mathrm{R} 5$, $\mathrm{R} 6, \mathrm{R} 7$ and $\mathrm{R} 8$ in protease production. All the bacterial strains represented bubble formation illustrating that they are also capable of catalase production. Cellulose production is performed by R1, R4, R5, R6, R7 and R8. 
Many previous studies showed that PGPB strains have the ability to produce plant hormones and are capable to stimulate cell division as well as elongation of plant cells and also alters activity of bacterial 1aminocyclopropane-1-carboxylate

(ACC) deaminase, that stop the ethylene, a plant growth inhibiting hormone to be produced [11, 12]. As bacteria are present in rhizosphere of plant in high number are of great importance in reference to change inorganic and organic substances into accessible plant nutrients that were previously unavailable and can influence the vegetative growth of different trees e.g. apple that's why one of the mechanisms used by PGPB to increase the growth of plants could be to increase the amount of available nutrients to plant and to increase the production of plant growth regulators [13]. Many previous studies acknowledged different bacterial strains with the ability to produce different plant growth regulators in rhizosphere of plant and these regulators include IAA, cytokinin and others and these regulators have positive effects in promoting plant growth and increase in yield [14-16]. On the other hand, oxogenous IAA has played its part in making survival of PGPB on host plant possible, increase efficiency and growth as well as proved its contribution in colonization [17].

Previous studies on PGPBs have proved the practical application of inoculation of these bacteria on commercial basis for improving production rate of vegetables that are having peat substrates with the aim to enhance vigor of plants and increased yield rate as well as helpful in controlling several diseases of roots $[18$, 19]. Many previous researches have reported that PGPB can also be a reason of causing the change in metabolism of plants as a result of their inoculation in plants, hence it was proved by interpreting the metabolic rate of these plant roots and different parts of roots like tissues and exudates of roots, it was also observed that not only roots but also metabolism of shoots both in control and normal conditions get effected by the inoculation of plant growth promoting bacteria.

\section{Conclusion}

It was concluded that the members of many PGPB functional groups can perform all together in the form of consortia or with their positive and contrary effects on plant growth and development. These positive effects can be achieved by application of different inoculation methods comprising of several kinds of microorganisms proved to be beneficial for plants in form of combination. On the other hand, the interactions between different bacterial strains being inoculated and the microorganisms that are present already in the rhizosphere or other parts of the plants also have great importance in this matter. Among eight strains two were used in this study that was inoculated in two varieties of maize to check their effect on roots of maize. These two bacterial strains R7 and R8 showed remarkable effects on different physiological parameters of maize plant roots. Five parameters of roots were estimated in this study. Bacterial strain showed noticeable effects on the developmental rate of roots like plants treated with R7 and R8 had an increase in their average root width and length was also increased after inoculation of bacteria.

\section{Authors' contributions}

Conceived and designed the experiments: SS Habib, Performed the experiments: S Naz \& A Mehmood, Analyzed the data: R Khan, Contributed materials/ analysis/ tools: I Badshah, Wrote the paper: SS Habib \& S Naz.

\section{References}

1. Middledrop PJM, Briglia M \& SalkinojaSalonen M (1990). Biodegradation of pentachlorophenol in natural polluted soil by inoculated Rhodococcus chlorophenolicus. Microb Ecol 20: 123139.

2. Sturz AV, Christie BR \& Novak J (2000). Bacterial endophytes: potential role in developing sustainable system of crop production. Crit Rev Plant Sci 19: 1-30.

3. Burd G, Dixon DG \& Glick BR (2000). Plant growth promoting bacteria that decrease heavy metal toxicity in plants. Can J Microbiol 46: 237-245. 
4. Compant S, Clement C \& Sessitch A (2010). Plant growth promoting bacteria in the rhizobacteria and endosphere of plants: their role, colonization, mechanisms involved and prospects for utilization. Soil Biol Biochem 42: 669-678.

5. Vale M, Seldin L, Araujo FF \& Lima R (2010). Plant growth promoting rhizobacteria: fundamentals and applications. In: Maheshwari DK Ed. Plant growth and health promoting bacteria. Springer Berlin, pp 21-43.

6. Schippers B, Scheffer RJ, Lugtenberg JJ \& Weisbek PJ (1995). Biocoating of seed with plant growth promoting rhizobacteria to improve plant establishment. Outlook Agric 24: 179-18.

7. Naseem H \& Bano A (2014). Role of plant-growth promoting rhizobacteria and their exopolysaccharide in drought tolerance of maize. J Plant Interactions 9: 689-701.

8. Ahmad MZ, Zahir A, Asghar HN \& Asghar M (2011). Inducing salt tolerance in mung bean through coinoculation with rhizobia and plant growth-promoting rhizobacteria containing aminocyclopropane-1-carboxylate deaminase. Can J Microbiol 57: 578-589.

9. Bano A \& Muqarab R (2017). Plant defense induced by PGPR against Spodoptera litura in tomato (Solanum lycopersicum L.) Plant Biol 19(3): 406412.

10. Singh P, Mohanta Tk \& Sinha AK (2015). Unraveling the intricate nexus of molecular mechanisms governing rice root development. OsMPK3/6 and auxin cytokinin interplay. Plos One 10: Steel RG and Torrie J (1960). Principles and procedures of statistics. Megraw-Hill Book Company, Inc New York Toronto London.

11. Patten CL \& Glick BR (2002). Role of Pseudomonas putida indoleacetic acid in development of the host plant root system. Appl Environ Microbiol 68: 3795-3801.
12. Penrose DM, Moffatt BA \& Glick BR (2001). Determination of 1aminocycopropane-1-carboxylic acid (ACC) to assess the effects of ACC deaminase-containing bacteria on roots of canola seedlings. Can J Microbiol 47: 7780.

13. Watanabe $M$, SuzukiA, Komori $S$ \& Bessho H (2004). Comparison of endogenous IAA and cytokinins in shoots of columnar and normal type apple trees. JJPn Soc Hort Sci 73: 19-24.

14. Bent E, Tuzun S, Chanway CP \& Enebak $S$ (2001). Alterations in plant growth and in hormone levels of lodgepole pines inoculated with rhizobacteria. Can $J$ Microbiol 47: 793-800.

15. Cook NC, Bellstedt DU \& Jacob G (2001). Endogenous cytokinin distribution patterns at budburst in Granny Smith and Braeburn apple shoots in relation to bud growth. Sci Hort 87: 53-63.

16. Gadagi RS, Krishnaraj PU, Kulkarni JH \& Sa T (2004). The effect of combined azospirillum inoculation and nitrogen fertilizer on plant growth promotion and yield response of the blanket flower Gaillardia pulchella. Sci. Hort 100: 573581.

17. Vandeputte O, Oden S, Mol A, Vereecke D, Goethals K, El Jaziri M \& Prinsen E (2005). Biosynthesis of auxin by the gram positive phytopathogen Rhodococcus fascians is controlled by compounds specific to infected plant tissues. Appl Environ Microb 71: 1169-1177.

18. Kokalis-Burelle N, Kloepper JW \& Reddy MS (2006). Plant growth promoting rhizobacteria as transplant amendments and their effects on indigenous rhizosphere microorganisms. Appl Soil Ecol 31(1-2): 91-100.

19. Kloepper JW, Ryu CM \& Zhang S (2004). Induced systemic resistance and promotion of plant growth by bacillus spp. Phytopathol 94(11): 1259-1266. 